\title{
Uma Abordagem Colaborativa para Aprendizagem de Programação Orientada a Objetos
}

\author{
Leonardo Davi Pereira Machado ${ }^{1}$, Carla Diacui M. Berkenbrock ${ }^{1}$, \\ Ivante Zuchi Siple ${ }^{2}$, Celso M. Hirata ${ }^{3}$ \\ ${ }^{1}$ Departamento de Ciência da Computação \\ ${ }^{2}$ Departamento de Matemática \\ Universidade do Estado de Santa Catarina (UDESC) \\ ${ }^{3}$ Divisão de Ciência da Computação \\ Instituto Tecnológico de Aeronáutica \\ leonardo.davi.machado@gmail.com, carla.berkenbrock@udesc.br \\ ivanete.siple@udesc.br, hirata@ita.br
}

\begin{abstract}
This paper presents a collaborative approach called Collaborative Session Cycle. In this approach, students work using different strategies: individually followed by group work, or directly in the group in order to exchange experiences and learn Object Oriented Programming (OOP). In this study we developed the mobile application entitled CLinClass to support the approach and we conducted a case study to demonstrate the applicability of the approach. The results indicate the potential of the approach to support the learning of computer programming concepts.
\end{abstract}

Resumo. Este artigo apresenta uma abordagem colaborativa chamada de $\mathrm{Ci}$ clo de Sessão Colaborativa. Nesta abordagem os alunos trabalham usando diferentes estratégias: individualmente seguida por um trabalho em grupo, ou diretamente em grupo a fim de trocar experiências e aprender Programação Orientada a Objetos (POO). Neste trabalho foi desenvolvida a aplicação móvel intitulada CLinClass para apoiar a abordagem utilizada e foi conduzido um estudo de caso para demonstrar a aplicabilidade da abordagem. Os resultados alcançados indicam o potencial da abordagem para apoiar a aprendizagem dos conceitos de programação de computadores.

\section{Introdução}

Nos cursos de computação, as disciplinas de Algoritmos, Linguagem de Programação e Programação Orientada a Objetos (POO) são reconhecidas como difíceis para os alunos e resultam num alto índice de reprovação e evasão [Barcelos et al. 2009, da Silva et al. 2009, Priesnitz Filho et al. 2012].

Pesquisadores e professores têm investigado e aplicado diversas técnicas, processos e estratégias, junto com recentes tecnologias tais como dispositivos móveis [Barcelos et al. 2009], lousa digital [Priesnitz Filho et al. 2012], jogos digitais [Rapkiewicz et al. 2006, da Silva et al. 2014] e ambientes virtuais [Salgado et al. 2013] a fim de facilitar a aprendizagem dos conceitos e técnicas de programação. Nós acreditamos que existe espaço para uma maior investigação e desenvolvimento de recursos 
para apoiar a aprendizagem de programação. Conjecturamos que processos devem ser flexíveis para acomodar diferentes formas de estratégias para atingir o objetivo de aprendizado, bem como devem existir ferramentas que deem suporte adequado aos processos.

As organizações em geral exigem que os seus profissionais tenham cada vez mais uma postura colaborativa a fim de que eles contribuam para o desenvolvimento de competências do grupo. Contudo, aprender a programar de forma colaborativa não é uma tarefa fácil, pois de acordo com [Castro et al. 2008] os alunos não estão acostumados a trabalhar em grupo para esta finalidade e envolve diferentes processos, estratégias, técnicas e tecnologias.

Neste trabalho é definida uma abordagem colaborativa de processo que acomoda duas estratégias para a aprendizagem de programação orientada a objetos. Para mostrar a viabilidade do processo, foi desenvolvido um aplicativo para dispositivos móveis e Web, o CLinClass, que pode ser integrado à prática do professor. O CLinClass considera requisitos de formação de grupo, autonomia, estratégias e percepção entre outros requisitos que foram apresentados em trabalhos anteriores [Machado et al. 2015, Machado et al. 2016]. Apresenta-se também um estudo de caso realizado na disciplina Programação Orientada a Objetos do curso de Ciência da Computação na Universidade do Estado de Santa Catarina.

O artigo está organizado da seguinte forma: a Seção 2 apresenta os trabalhos correlatos; a Seção 3 apresenta a abordagem utilizada para empregar a aprendizagem colaborativa em sala de aula; na Seção 4 é apresentado o aplicativo CLinClass; a Seção 5 relata o estudo de caso realizado; na Seção 6 é realizada uma discussão sobre os resultados alcançados; e por fim na Seção 7 são apresentadas as considerações finais.

\section{Trabalhos correlatos}

Pesquisadores têm empreendido esforços para aplicar a colaboração no contexto acadêmico com o objetivo de obter melhor desempenho na aprendizagem dos alunos. $\mathrm{Na}$ sequência, descrevemos esses trabalhos e alguns propiciaram características importantes para a abordagem proposta, bem como para o desenvolvimento do aplicativo.

[Siqueira and Alcântara 2003] inserem a colaboração no contexto da educação superior como meio de inovar a prática pedagógica. Os autores afirmam que "no papel de agente de transição cultural, cabe ao docente desenvolver as habilidades de trabalhar em grupo, para que o aluno possa contribuir para o grupo e para o seu próprio desenvolvimento".

[Alcântara et al. 2004] aplicam a aprendizagem colaborativa em três cursos de graduação, utilizando uma abordagem pela qual os alunos realizavam atividades individuais e depois coletivas. Segundo os autores "utilizar os trabalhos individuais para desenvolver o trabalho em grupo acabou sendo uma das etapas mais produtivas do processo".

[Castro et al. 2008] apresentam um esquema de progressão de aprendizagem de programação em grupo. O esquema foi avaliado em estudo de caso realizado na disciplina de introdução de programação na Universidade Federal do Amazonas. O esquema prevê uma transição gradual da prática individual para a programação em grupo. Os autores afirmam que tal transição é necessária, pois os estudantes não estão acostumados a 
trabalhar em grupo. O estudo apontou uma boa aceitabilidade e rendimento dos alunos nas sessões de laboratório.

[Valdivia et al. 2009] aplicaram a aprendizagem colaborativa em duas disciplinas do curso de Ciência da Computação, Introdução a Programação e Fundamentos de Linguagens de Programação. Para apoiar a aprendizagem foi utilizado um aplicativo de PDA (Personal Digital Assistent), denominado CANA (Collaborative Answer Negotiation Activity), que disponibiliza aos alunos um conjunto de questões de múltipla escolha onde cada aluno deveria apresentar uma resposta para cada questão e depois em grupo, os alunos deveriam negociar uma resposta de consenso do grupo.

[Alvarez et al. 2011] apresentaram o CollPad, um aplicativo para PDA desenvolvido para apoiar a aprendizagem colaborativa. O aplicativo foi utilizado para fins de avaliação em duas disciplinas do curso de Ciência da Computação, Gestão do Conhecimento e Interação Humano Computador. O aplicativo permite dividir os alunos aleatoriamente em pequenos grupos, depois o professor envia uma questão aberta para os alunos. Cada aluno deve responder essa questão em seu dispositivo e depois o grupo deve escolher uma resposta para ser a resposta do grupo. Se desejarem, os alunos podem escrever uma nova resposta de forma coletiva, nesse caso o aplicativo seleciona um membro do grupo para fazer a escrita e os outros membros confirmam se aceitam essa nova resposta. Se não aceitarem a resposta é descartada e outro membro do grupo é selecionado para escrever uma nova resposta, repetindo o processo. Após ter a concordância de todos os membros, a resposta é encaminhada ao professor.

Os trabalhos citados apresentam diferentes abordagens de colaboração para a aprendizagem. Entretanto, algumas características comuns são evidenciadas na forma de organização das atividades realizadas: os alunos trabalham individualmente previamente e posteriormente trabalham em grupo com intuito de chegar a um consenso sobre a solução. Essa característica também foi adotada como uma opção na abordagem de processo que descrevemos na próxima seção.

\section{Ciclo de Sessão Colaborativa}

A aprendizagem colaborativa possibilita práticas educacionais diferenciadas daquela que, normalmente, o professor expõe um determinado assunto e na sequência submete os alunos a exercícios para realizar a fixação do conteúdo, depois torna a expor um novo conteúdo e novamente submete os alunos a novos exercícios, haja vista que as interações entre pares constituem elementos importantes na aprendizagem colaborativa.

No processo de ensino, a prática realizada pelo professor privilegia, em muitos casos, a repetição e memorização em detrimento da compreensão. Assim, os alunos seguem os exemplos resolvidos em sala de aula para resolver extensas listas de exercícios que seguem determinados padrões [de Oliveira 2014].

No contexto do ensino de POO, essa abordagem, em muitos casos, não favorece a troca de conhecimento e a discussão entre os alunos para encontrar a melhor solução para o problema proposto. Isso ocorre porque o desenvolvimento de um programa, principalmente usando o paradigma de orientação a objetos, exige além de lógica de programação, uma abstração diferente que inclui conceitos de objeto, classe, chamada de método, encapsulamento, composição e herança. 
Por outro lado, percebe-se que os alunos quando estudam em grupo têm melhor rendimento na aprendizagem, pois essa estratégia de aprendizagem favorece a ocorrência e resolução de dúvidas, retenção do conhecimento e a satisfação do aluno [Koshino 2010, p. 18]. Dessa forma, propõe-se uma abordagem colaborativa de processo denominada de Ciclo de Sessão Colaborativa. Na abordagem proposta, inicialmente o professor define um problema aos alunos e o professor seleciona uma estratégia de trabalho. Na primeira estratégia, os alunos trabalham individualmente e depois trabalham em grupo. Na segunda estratégia, os alunos trabalham em grupo diretamente, conforme mostra a Figura 1. No trabalho em grupo, os alunos trabalham para chegar a uma solução de consenso.

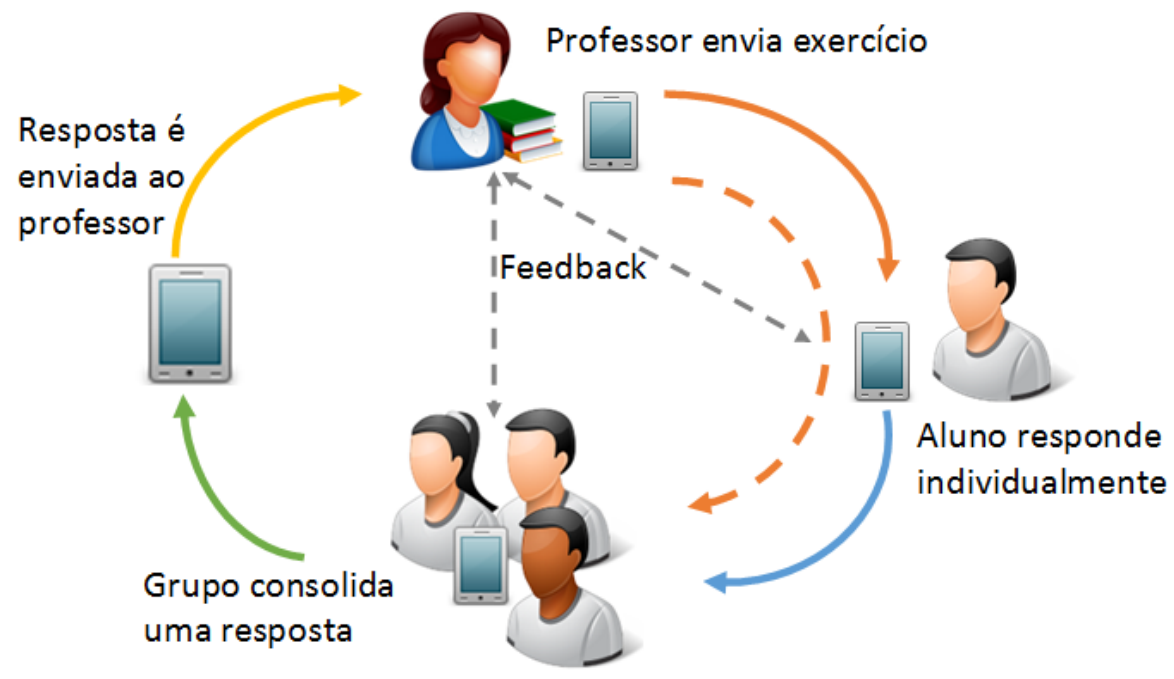

Figura 1. Ciclo de sessão colaborativa

A abordagem proposta fundamenta-se também no conceito de sala de aula invertida e na prática da aprendizagem colaborativa. $O$ conceito de sala de aula invertida diz respeito a inversão que ocorre no método de ensino, onde o aluno estuda o conteúdo teórico antes da aula presencial e em sala de aula tira as dúvidas, discute os pontos indicados pelo professor e desenvolve os exercícios [Piva Jr. and Cortelazzo 2015, Valente 2014]. Do ponto de vista prático, pode-se citar os trabalhos de [Siqueira and Alcântara 2003, Alcântara et al. 2004, Valdivia et al. 2009, Alvarez et al. 2011], conforme apresentados na Seção 2, nas experiências relatadas nessas pesquisas os alunos trabalham individualmente e também em grupo.

Assim, o trabalho individual é executado pelo aluno quando ele estiver em casa, ou qualquer outro ambiente que não seja a sala de aula. Neste momento, o aluno pode consultar os materiais fornecidos pelo professor, livros ou outra fonte de informações que possibilite a execução das atividades propostas. Além disso, é um momento para o aluno refletir os conceitos teóricos e conseguir elaborar uma argumentação para expor aos seus colegas de grupo. Após terem realizado individualmente as atividades os alunos se reúnem em grupos, em sala de aula, para discutir o objeto de estudo a fim de chegar juntos a uma solução para o problema trabalhado. Nesse momento, o aluno tem a oportunidade de expor suas dúvidas, testar suas hipóteses, esboçar suas conjecturas e criar estratégias para resolver o problema. Essa discussão em grupo favorece a troca de conhecimento e experiência para a resolução de problemas. Assim o grupo constrói um consenso sobre 
qual é a melhor solução frente ao problema abordado, e esta solução que é encaminhada para o professor como a resposta do grupo.

Nesse processo, o professor pode monitorar o andamento das atividades e, a qualquer momento, pode dar um feedback para um aluno ou grupo, fornecendo dicas, tirando dúvidas e motivando os alunos a continuarem a execução da tarefa.

$\mathrm{Na}$ aprendizagem colaborativa, o importante é a interação que ocorre durante o trabalho em grupo. Contudo, conforme as pesquisas mencionadas acima, o trabalho individual executado previamente ao trabalho em grupo também tem sua importância, pois pode dar ao aluno recursos para que a interação em grupo seja mais efetiva, permitindo que ele expresse seu pensamento e sua opinião de forma mais clara contribuindo para o aprendizado dos colegas e seu próprio aprendizado.

Em algumas situações, os desafios das atividades não requer os alunos trabalhem individualmente, por exemplo a atividade para se chegar a um consenso sobre conceitos de programação. Nesses casos, o professor deve ter a possibilidade de adotar a estratégia de colocar diretamente a atividade para trabalho dos alunos em grupo.

Pelos motivos apresentados é que o Ciclo de Sessão Colaborativa apresenta a possibilidade de trabalho individual seguido de trabalho em grupo ou trabalho em grupo diretamente.

O ciclo colaborativo apresentado pode ser utilizado mediado por diferentes recursos. Contudo, com a percepção de que os jovens têm facilidade no uso dos dispositivos móveis, o professor deve buscar formas de aproveitar essa tecnologia para melhorar o processo de aprendizagem. Dessa forma, foi desenvolvido o aplicativo chamado CLinClass que utiliza o Ciclo de Sessão Colaborativa a fim de apoiar a aprendizagem colaborativa com os alunos da disciplina Programação Orientada a Objetos. Na próxima seção, o aplicativo é descrito.

\section{CLinClass}

$\mathrm{O}$ aplicativo CLinClass (Collaborative Learning in Classroom) foi desenvolvido com o objetivo de apoiar o uso da aprendizagem colaborativa de programação de computadores de nível básico para o Ciclo de Sessão Colaborativa proposto. O aplicativo foi projetado para ser utilizado em smartphones e tablets que executem os sistemas operacionais Android, iOS ou Windows Phone. O aplicativo implementa um conjunto de requisitos funcionais e requisitos para apoiar a colaboração e a aprendizagem, tais requisitos são descritos nos trabalhos [Machado et al. 2015, Machado et al. 2016].

Como recurso pedagógico o aplicativo disponibiliza três tipos de atividades que são: questões de múltipla escolha; problema de Parsons; problemas abertos. Os problemas abertos são aqueles em que o aluno tem um campo de texto disponível para colocar livremente sua resposta, dependendo do enunciado do problema a resposta pode ser uma explicação ou o código de um algoritmo. O problema de Parsons é uma atividade que se assemelha a um quebra cabeça cujo o objetivo é reordenar os fragmentos de código a fim de chegar no algoritmo correto [Parsons and Haden 2006]. Na Figura 2 é apresentado um exemplo dos três tipos de atividades que o CLinClass disponibiliza.

Para favorecer a colaboração o aplicativo permite a comunicação entre os alunos e professor, por meio da troca de mensagens de texto, possibilitando que eles esclareçam 


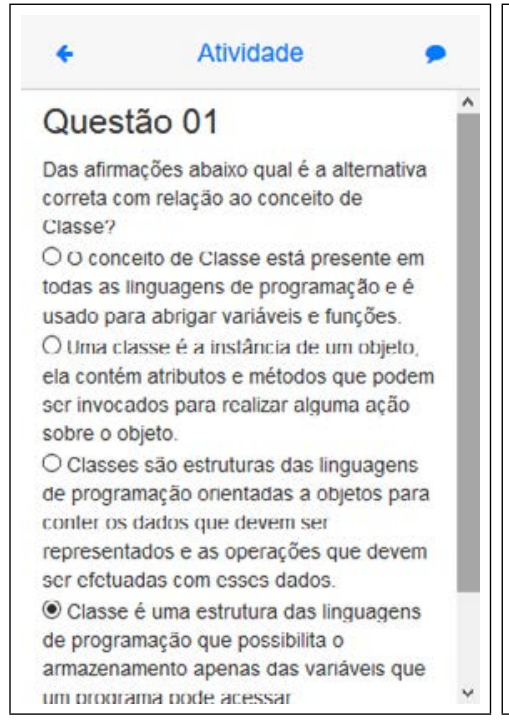

(a) Múltipla escolha

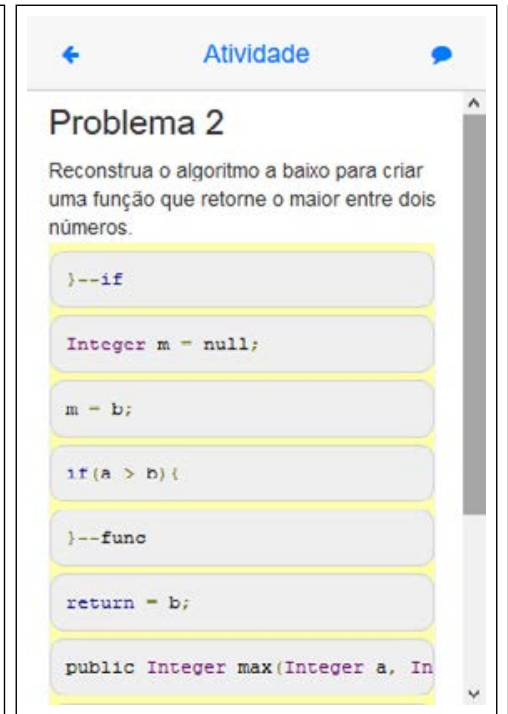

(b) Parsons Problem

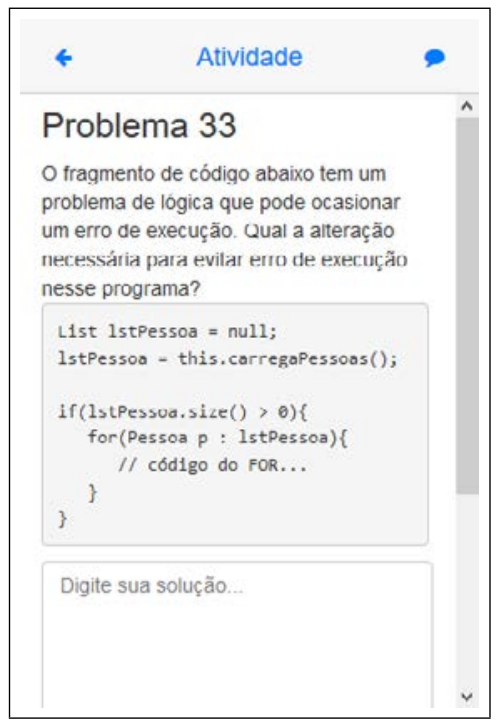

(c) Problema aberto

Figura 2. Tipos de atividades

dúvidas com os pares, ou solicitem orientações ao professor. O aplicativo possibilita também a percepção de trabalho dos outros membros do grupo, sendo possível visualizar quais atividades cada membro já realizou e qual a última vez que as mensagens foram lidas. Na Figura 3 são apresentadas as telas de mensagens e de informações do grupo.

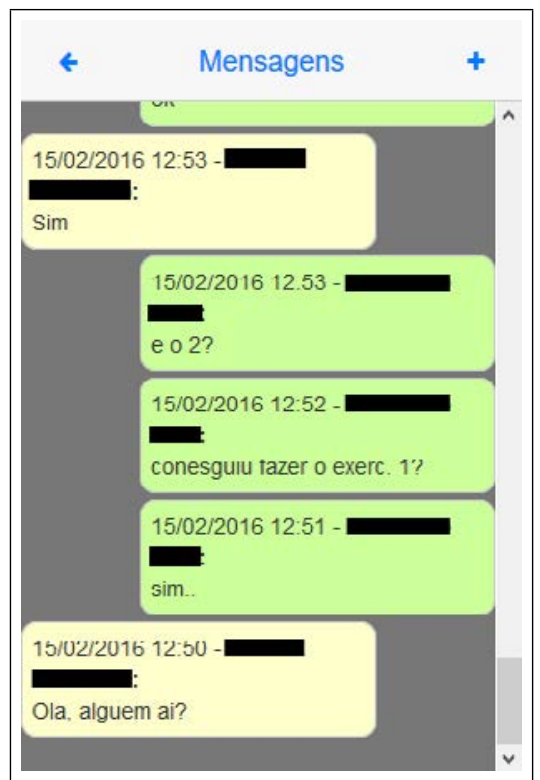

(a) Mensagens

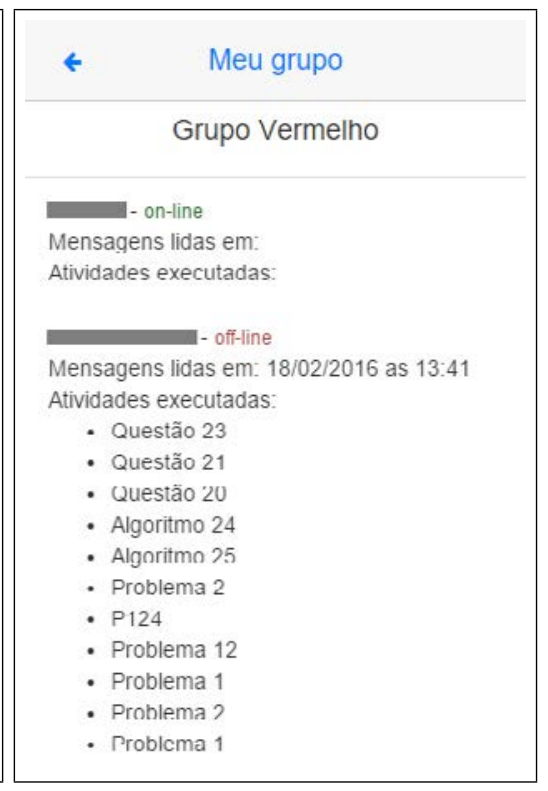

(b) Meu grupo

Figura 3. Telas CLinClass

\section{Estudo de caso}

Para avaliar a utilização da abordagem proposta, Ciclo de Sessão Colaborativa, e o aplicativo CLinClass, foi realizado um estudo de caso com 26 alunos da disciplina 
de Programação Orientada a Objetos do terceiro semestre do curso de Ciência da Computação da Universidade do Estado de Santa Catarina. As duas possibilidades de estratégia foram investigadas: a estratégia em que os alunos trabalham diretamente em grupo e a estratégia em que os alunos trabalham individualmente e depois trabalham em grupo.

Inicialmente foi aplicado um questionário com o intuito de obter o perfil dos alunos quanto ao gênero, idade, dispositivos que possuíam e a configuração desses dispositivos. Todos os integrantes da turma são rapazes, com idade média de dezenove anos. Todos os alunos possuem smartphones e $24 \%$ possuem tablets.

Buscou-se também informações sobre a configuração, especialmente o sistema operacional, dos smartphones pois o aplicativo provia duas versões para utilização. $\mathrm{Na}$ Figura 4 percebe-se a predominância do sistema operacional Android nos dispositivos e os tamanhos de telas de 4"e 5".

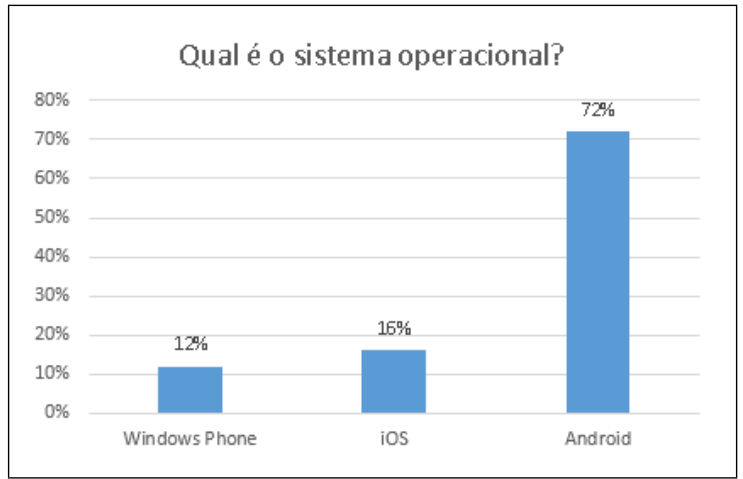

(a) Sistema Operacional

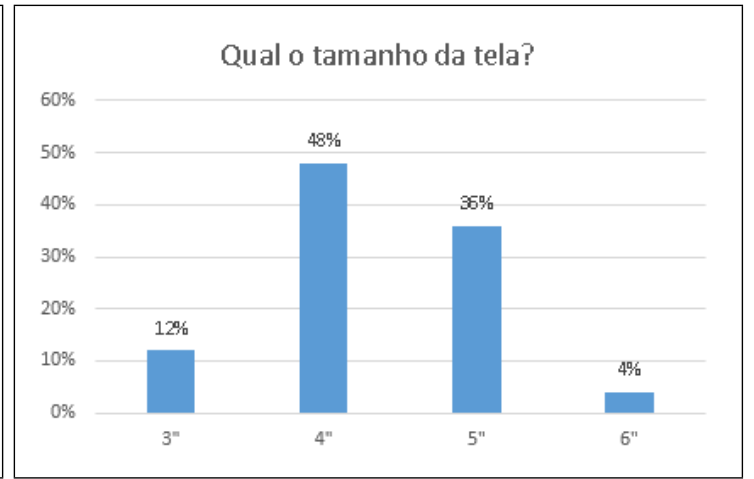

(b) Tamanho da tela

Figura 4. Configuração smartphones

Com essas informações pôde ser traçado a organização da prática realizada em sala de aula. Os alunos utilizaram duas versões do aplicativo. Os alunos que possuíam dispositivos com sistema operacional Android, fizeram a instalação do aplicativo no dispositivo, já os alunos que possuíam sistema operacional Windows Phone ou iOS utilizaram a versão Web acessado por meio do navegador web do dispositivo.

\subsection{Caso 1}

No primeiro encontro os alunos foram divididos em cinco grupos de até seis alunos, os próprios alunos puderam escolher o grupo em que queriam se inserir, pelo aplicativo. O professor da disciplina precisou intervir apenas em dois casos de alunos que estavam chegando na turma nesse mesmo dia e por esse motivo ainda estavam deslocados em relação a turma. Foi utilizada a estratégia dos alunos trabalharem diretamente em grupo para responderem dez questões de múltipla escolha versando sobre os conceitos teóricos de orientação a objetos. Na Figura 2(a) é apresentado um exemplo dessa atividade.

Após executarem todas as atividades, os alunos foram submetidos a um questionário para avaliar a satisfação do aluno com relação ao trabalho realizado e forma de se comunicar com colegas e professor. O questionário foi respondido por 22 alunos. As perguntas constantes no questionário são apresentadas na Tabela 1. 
Tabela 1. Questionário Caso 1

\begin{tabular}{|c|c|}
\hline Perguntas & Opções de resposta \\
\hline $\begin{array}{l}\text { 1) Qual é o seu nível de satisfação em relação as atividades } \\
\text { propostas? }\end{array}$ & \multirow[t]{2}{*}{$\begin{array}{l}\text { Muito insatisfeito, In- } \\
\text { satisfeito, Satisfeito e } \\
\text { Muito satisfeito }\end{array}$} \\
\hline $\begin{array}{l}\text { 2) Qual é o seu nível de satisfação em relação a forma de se } \\
\text { comunicar com os colegas e professor? }\end{array}$ & \\
\hline $\begin{array}{l}\text { 3) Qual é a sua opinião em relação a forma que os grupos } \\
\text { foram criados? }\end{array}$ & \multirow[t]{3}{*}{$\begin{array}{l}\text { Péssimo, Ruim, Bom e } \\
\text { Muito bom }\end{array}$} \\
\hline $\begin{array}{l}\text { 4) Qual é a sua opinião em relação a adequação do conteúdo } \\
\text { ao tamanho da tela de seu dispositivo? }\end{array}$ & \\
\hline $\begin{array}{l}\text { 5) Como você avalia o processo de construção da resposta } \\
\text { do grupo para cada atividade e a geração do consenso? }\end{array}$ & \\
\hline $\begin{array}{l}\text { 6) A ferramenta é flexível, permitindo trabalhar on-line e } \\
\text { off-line, além de executar as atividades na ordem que me é } \\
\text { mais conveniente? }\end{array}$ & \multirow[t]{2}{*}{$\begin{array}{l}\text { Discordo plenamente, } \\
\text { Discordo, Concordo e } \\
\text { Concordo plenamente }\end{array}$} \\
\hline $\begin{array}{l}\text { 7) O aplicativo fornece meios para perceber como está o } \\
\text { andamento do trabalho dos colegas? }\end{array}$ & \\
\hline
\end{tabular}

Na Figura 5 percebe-se que $73 \%$ dos alunos se sentiram satisfeitos com as atividades propostas. Já quanto a forma de se comunicar com colegas e professor, $68 \%$ dos alunos se dizem satisfeitos.

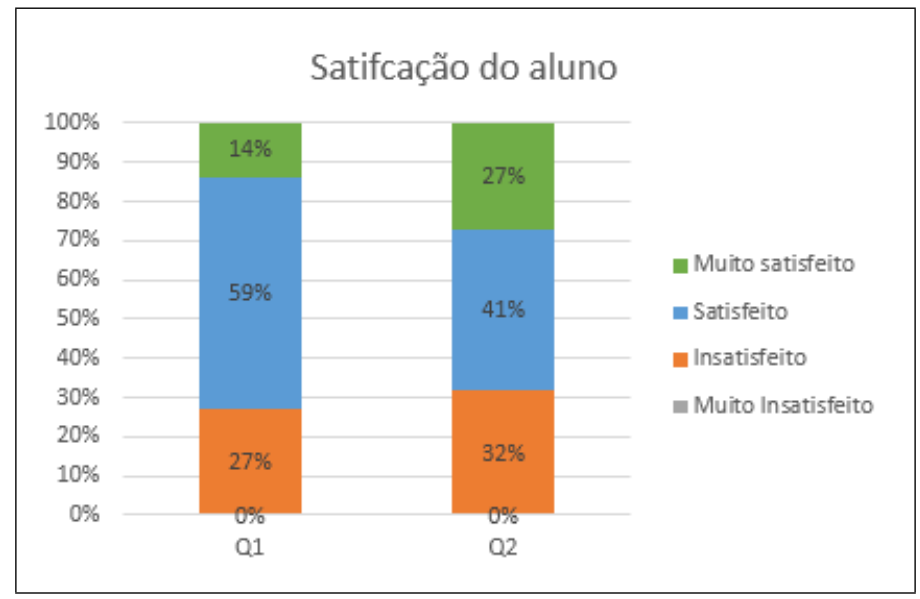

Figura 5. Satisfação do aluno com relação ao trabalho realizado (Q1) e forma de
se comunicar com colegas e professor (Q2)

Como mencionado anteriormente os alunos puderam escolher livremente em qual grupo entrar, na Figura 6, percebe-se que $91 \%$ dos alunos acharam boa essa forma de criar os grupos. No que diz respeito a adequação do conteúdo ao tamanho da tela, $86 \%$ dos alunos acharam que o aplicativo apresenta uma boa adequação ao tamanho do dispositivo. O processo de construção da resposta do grupo foi avaliado como bom por $91 \%$ dos alunos que participaram da pesquisa.

As questões 6 e 7 têm por finalidade verificar a visão do aluno, no sentido de concordância ou não das afirmações apresentadas. Percebe-se na Figura 7, 82\% dos alunos 


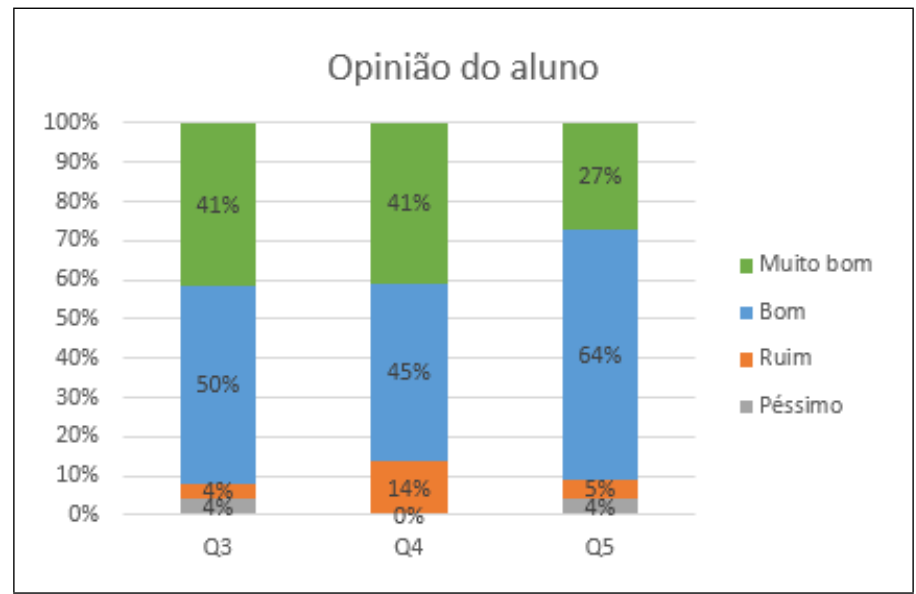

Figura 6. Opinião do aluno sobre a forma de criação dos grupos (Q3), adequação do conteúdo à tela (Q4) e processo de construção da resposta (Q5)

concordam que a ferramenta é flexível, permitindo que as atividades sejam executadas na sequência que seja mais adequada a cada aluno. Além disso, $81 \%$ dos alunos concordam que o aplicativo fornece meios para ter a percepção de como está o andamento do trabalho dos colegas.

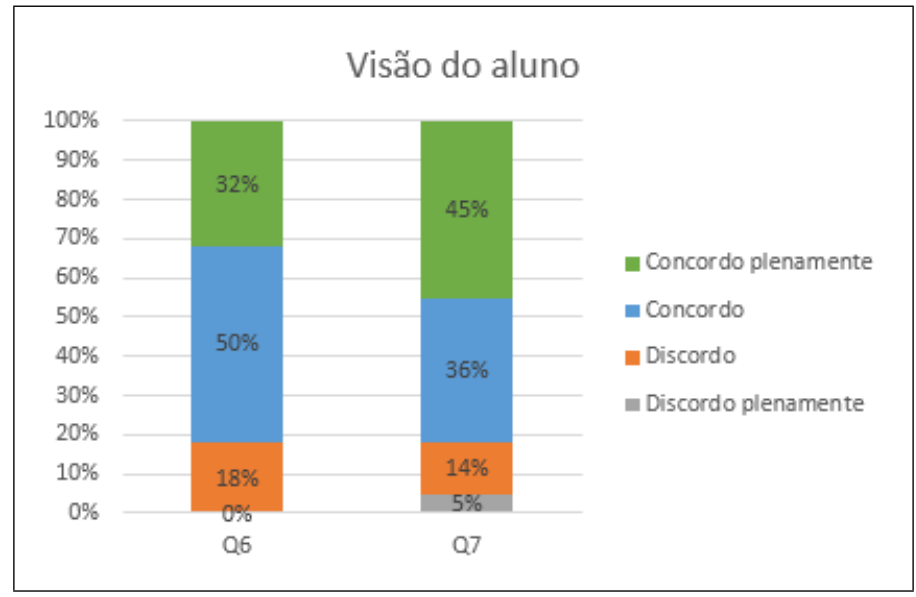

Figura 7. Visão do aluno quanto à flexibilidade da ferramenta (Q6) e percepção do andamento de trabalho (Q7)

\subsection{Caso 2}

No segundo caso estudado os alunos foram mantidos na mesma formação de grupos do Caso 1. Foram passados 5 problemas abertos para serem resolvidos, a Figura 2(c) apresenta um exemplo desse tipo de problema. Seguindo o conceito de sala de aula invertida, os alunos deveriam resolver os problemas em casa, elaborando individualmente uma solução para cada problema. Na aula seguinte os grupos voltaram a se reunir para gerar um consenso quanto a solução de cada problema.

Após os alunos trabalharem em grupo, o questionário foi aplicado novamente, porém com algumas adaptações, a fim de levantar a opinião dos alunos quanto ao trabalho realizado, a Tabela 2 apresenta as perguntas do questionário. 
Tabela 2. Questionário Caso 2

\begin{tabular}{|c|c|}
\hline Perguntas & Opções de resposta \\
\hline $\begin{array}{l}\text { 1) Qual é o seu nível de satisfação em relação as atividades } \\
\text { propostas? }\end{array}$ & \multirow[t]{4}{*}{$\begin{array}{l}\text { Muito insatisfeito, In- } \\
\text { satisfeito, Satisfeito e } \\
\text { Muito satisfeito }\end{array}$} \\
\hline $\begin{array}{l}\text { 2) Qual é o seu nível de satisfação em relação ao feedback } \\
\text { fornecido pelo professor? }\end{array}$ & \\
\hline $\begin{array}{l}\text { 3) Qual é o seu nível de satisfação em relação a forma de se } \\
\text { comunicar com os colegas? }\end{array}$ & \\
\hline $\begin{array}{l}\text { 4) Qual é o seu nível de satisfação em relação a forma de se } \\
\text { comunicar com o professor? }\end{array}$ & \\
\hline $\begin{array}{l}\text { 5) Qual é a sua opinião em relação a forma que os grupos } \\
\text { foram criados? }\end{array}$ & \multirow[t]{4}{*}{$\begin{array}{l}\text { Péssimo, Ruim, Bom e } \\
\text { Muito bom }\end{array}$} \\
\hline $\begin{array}{l}\text { 6) Qual é a sua opinião em relação a adequação do conteúdo } \\
\text { ao tamanho da tela de seu dispositivo? }\end{array}$ & \\
\hline $\begin{array}{l}\text { 7) Como você avalia o processo de construção da resposta } \\
\text { do grupo para cada atividade? }\end{array}$ & \\
\hline $\begin{array}{l}\text { 8) Como você avalia a geração do consenso para cada ativi- } \\
\text { dade? }\end{array}$ & \\
\hline $\begin{array}{l}\text { 9) A ferramenta é flexível? Permite trabalhar on-line e off- } \\
\text { line, além de executar as atividades na ordem que me é mais } \\
\text { conveniente? }\end{array}$ & \multirow[t]{3}{*}{$\begin{array}{l}\text { Discordo plenamente, } \\
\text { Discordo, Concordo e } \\
\text { Concordo plenamente }\end{array}$} \\
\hline $\begin{array}{l}\text { 10) Trabalhar individualmente e depois em grupo contri- } \\
\text { buiu para a aprendizagem em relação ao assunto de cada } \\
\text { atividade? }\end{array}$ & \\
\hline $\begin{array}{l}\text { 11) O aplicativo fornece meios para perceber como está o } \\
\text { andamento do trabalho dos colegas? }\end{array}$ & \\
\hline
\end{tabular}

O questionário foi respondido por 19 alunos. Quanto à satisfação, conforme mostra a Figura 8, percebe-se que os alunos ficaram mais insatisfeitos em relação as atividades propostas (53\%) e ao feedback fornecido pelo professor (52\%). No quesito comunicação os alunos apresentaram mais satisfação em relação a forma de se comunicar com colegas (94\%) e com o professor (68\%).

Quanto a opinião dos alunos, conforme a Figura 9, percebe-se que eles acharam boa a forma de geração do grupo (84\%) e a adequação do conteúdo ao tamanho da tela do dispositivo (79\%). Os alunos também acharam bom o processo de construção da resposta do grupo (84\%) e a geração do consenso (84\%).

Quanto a visão dos alunos, a Figura 10 mostra que $79 \%$ dos alunos concordam que a ferramenta é flexível. Com relação a sequencia de trabalho individual e trabalho em grupo, $79 \%$ dos alunos concordam que isso contribuiu para a aprendizagem. Com relação a percepção ao andamento do trabalho dos colegas, $85 \%$ dos alunos concordam que a ferramenta disponibiliza meios para se perceber quais atividades os colegas do grupo já executaram. 


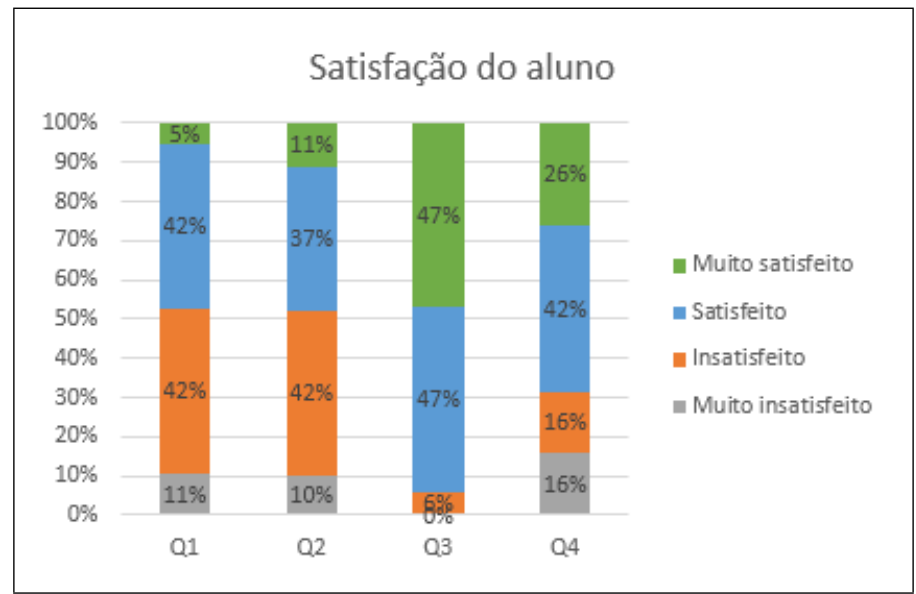

Figura 8. Satisfação dos alunos em relação as atividades propostas (Q1), feedback do professor (Q2), forma de comunicação com colegas (Q3) e forma de comunicação com professor (Q4)

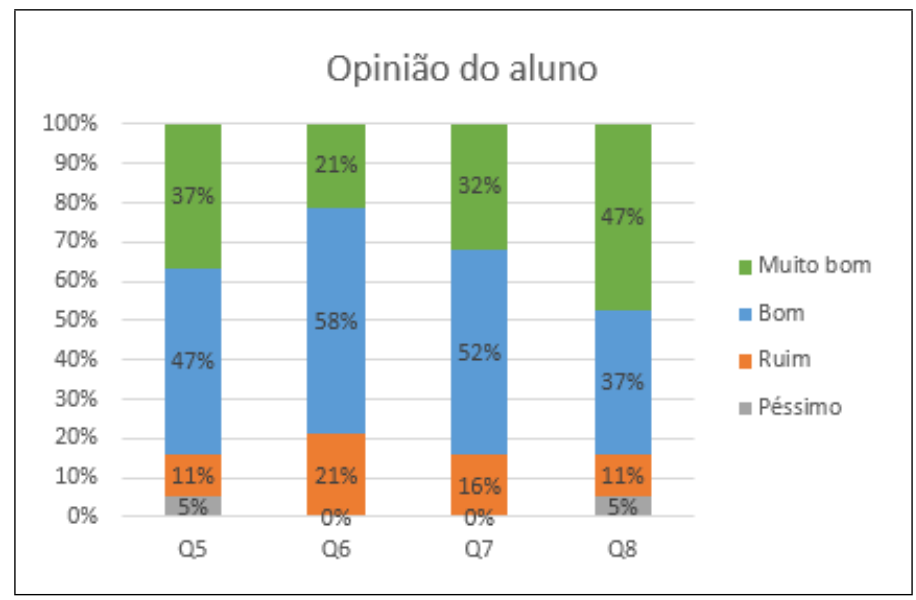

Figura 9. Opinião dos alunos com relação a forma de criação do grupo (Q5), adequação do conteúdo ao tamanho da tela (Q6), processo de contrução da resposta (Q7) e forma de geração de consenso (Q8)

\section{Discussão}

Conforme apresentado na seção anterior, os dois casos estudados têm algumas diferenças. A primeira diz respeito a forma como os alunos trabalharam, no Caso 1 os alunos realizaram apenas o trabalho em grupo enquanto que no Caso 2 foi utilizado o conceito de sala de aula invertida, onde os alunos tiveram que trabalhar individualmente e depois em grupo. A segunda diferença é em relação ao tipo de atividade executada, no Caso 1 foram aplicadas questões de múltipla escolha e no Caso 2 foram trabalhados problemas abertos onde o nível de dificuldade de cada atividade era maior do que no Caso 1.

Analisando o resultado dos questionários percebe-se que a satisfação dos alunos em relação as atividades propostas apresentou diminuição de $26 \%$, caindo de $73 \%$ no Caso 1 para $47 \%$ no Caso 2. Essa diminuição na satisfação dos alunos pode estar relacionada ao nível de complexidade que os problemas abertos apresentavam, pois eles foram elaborados para fazer com que os alunos pesquisassem novas informações e assim elaborassem uma solução para o problema. Os resultados do Caso 1 evidenciam que a al- 


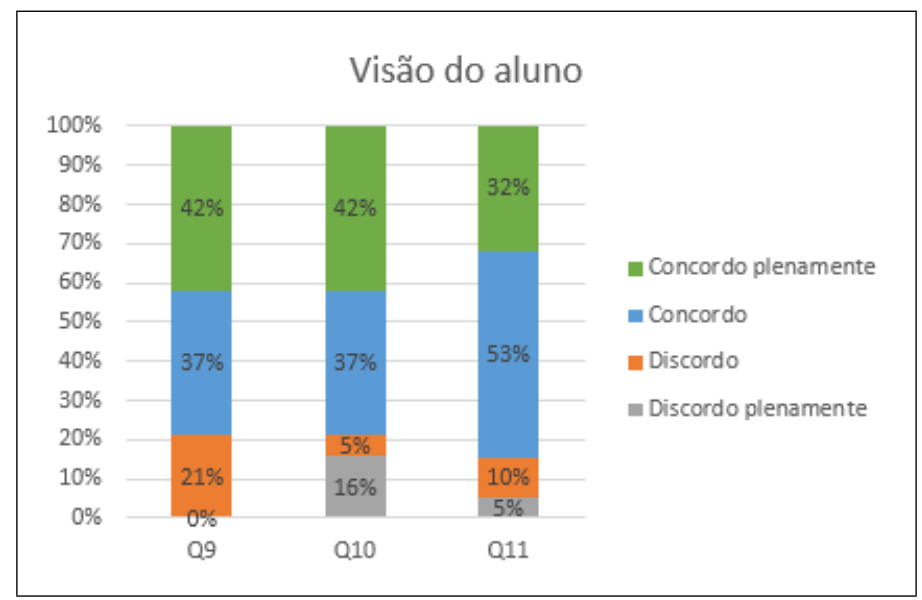

Figura 10. Visão dos alunos com relação à flexibilidade da ferramenta (online/offline) (Q9), sequência trabalho individual e trabalho em grupo (Q10) e percepção provida pela ferramenta das atividades realizadas pelos colegas (Q11)

ternativa de estratégia onde os alunos trabalham diretamente em grupo tem sua utilidade.

Antes de ser realizado o Caso 2 o professor da disciplina forneceu um feedback aos alunos em relação as atividades executadas anteriormente, passando quais foram os erros e os acertos de cada grupo. Porém, ao serem questionados sobre a satisfação em relação ao feedback fornecido pelo professor percebe-se um alto índice de insatisfação $(52 \%)$. Esse fato precisa ser melhor estudado para compreender se a insatisfação dos alunos é em relação a forma que o feedback foi fornecido, ou seja, mensagem de texto enviado pelo professor por meio do aplicativo, ou se os alunos ficaram insatisfeitos com o desempenho que eles obtiveram nas atividades propostas.

O mecanismo para o fornecimento do feedback é a mensagem de texto, que é o mesmo utilizado para a comunicação entre aluno-aluno e aluno-professor. Quanto a comunicação, 94\% dos alunos se dizem satisfeitos com a forma de se comunicar com os colegas e $68 \%$ se dizem satisfeitos com a forma de comunicação com o professor.

Quanto a flexibilidade da ferramenta, na visão dos alunos, $79 \%$ concordam que a ferramenta é flexível (online/offline) depois de realizado o Caso 2. Esse percentual foi de $82 \%$ no Caso 1. Quanto a percepção dos trabalhos realizados pelos colegas de grupo, no Caso 2, 85\% dos alunos concordam que o aplicativo fornece meios para saber quais atividades os membros do grupo já realizaram. Com o trabalho individual realizado em casa é importante que os alunos consigam saber como está o andamento do trabalho dos colegas para poderem trocar informações sobre a resolução dos problemas. O objetivo não é que um aluno passe inteiramente a resposta para o outro, mas sim que consiga compartilhar os conhecimentos necessários para que o colega consiga por si mesmo elaborar uma solução para o problema trabalhado.

Conforme já mencionado, no Caso 2 os alunos primeiro resolveram individualmente os 5 problemas propostos e depois, em grupo, chegaram a um consenso da melhor solução para cada problema. Ao serem questionados se o trabalhado individual e depois em grupo contribuiu para o aprendizado do assunto abordado em cada atividade, $79 \%$ dos alunos se manifestaram concordando que houve uma contribuição no aprendizado. 


\section{Considerações finais}

Este artigo apresentou uma abordagem colaborativa chamada de Ciclo de Sessão Colaborativa, na qual os alunos recebem atividades/problemas para serem resolvidos individualmente e depois é realizado uma discussão em grupo para criar um consenso sobre a melhor solução para o problema trabalhado. Nessa abordagem, duas alternativas de estratégia podem ser realizadas: os alunos podem trabalhar diretamente em grupo ou os alunos podem trabalhar individualmente e depois trabalhar em grupo. Foi apresentado também o aplicativo CLinClass, desenvolvido para apoiar a utilização do ciclo na disciplina Programação Orientada a Objetos, bem como o estudo de caso realizado para avaliar a utilização do ciclo e do aplicativo CLinClass.

Comparando o aplicativo CLinClass com os aplicativos CANA e CollPad, apresentados na seção 2, percebe-se que os três aplicativos fornecem a possibilidade de trabalhar com atividades de questões de múltipla escolha e com a interação de trabalho individual seguido de trabalho em grupo. Contudo, o CLinClass amplia as possibilidades do docente, permitindo os alunos trabalharem com problemas abertos e com os Parsons Problems, bem como permitindo o trabalho diretamente em grupo. Dessa forma o docente pode, conforme o conteúdo ministrado em aula, escolher quais tipos de atividades utilizar e qual a estratégia a ser aplicada para poder obter um melhor resultado na aprendizagem dos alunos.

Os resultados alcançados até o momento indicam que a abordagem utilizada tem o potencial de favorecer o aprendizado dos alunos. Contudo, o estudo está em andamento, sendo necessário realizar mais interações com os alunos para eles se acostumarem com a abordagem utilizada e com o trabalho colaborativo.

\section{Referências}

Alcântara, P. R., Siqueira, L. M. M., and Valaski, S. (2004). Vivenciando a aprendizagem colaborativa em sala de aula: experiências no ensino superior. Revista Diálogo Educacional, 4(12):169 - 188.

Alvarez, C., Alarcon, R., and Nussbaum, M. (2011). Implementing collaborative learning activities in the classroom supported by one-to-one mobile computing: A design-based process. The Journal of System and Software, 84:1961-1976.

Barcelos, R., Tarouco, L., and Bercht, M. (2009). O uso de mobile learning no ensino de algoritmos. RENOTE - Revista Novas Tecnologias na Educação, 7(2):327-337.

Castro, T., Castro, A., and Fuks, H. (2008). Aprendendo a programar em grupo. In Sistemas Colaborativos, 2008 Simpósio Brasileiro de, pages 45-54.

da Silva, I., SILVA, I., and SANTOS, M. (2009). Análise de problemas e soluções aplicadas ao ensino de disciplinas introdutórias de programação. IX Jornada de Ensino, Pesquisa e Extensão - JEPEX 2009.

da Silva, T. S. C., de A. R. Tedesco, P. C., and de Melo, J. C. B. (2014). A importância da motivação dos estudantes e o uso de técnicas de engajamento para apoiar a escolha de jogos no ensino de programação. In XXV Simpósio Brasileiro de Informática na Educação - SBIE 2014. 
de Oliveira, F. L. (2014). A produção de conhecimento matemático acerca de funções de duas variáveis em um coletivo de seres-humanos-com-mídias. Master's thesis, Universidade Federal de Ouro Preto.

Koshino, P. (2010). A aprendizagem e as interações em um treinamento a distância. Master's thesis, Universidade de Brasília.

Machado, L. D. P., Berkenbrock, C. D. M., and Siple, I. Z. (2016). Desenvolvimento de aplicativos para aprendizagem colaborativa apoiada por dispositivos móveis: uma análise dos requisitos. In COMPUTER ON THE BEACH 2016.

Machado, L. D. P., Berkenbrock, C. D. M., Siple, I. Z., and Hirata, C. M. (2015). Utilizando dispositivos móveis para apoiar a aprendizagem colaborativa baseada em problemas. In XII Simpósio Brasileiro de Sistemas Colaborativos - SBSC 2015.

Parsons, D. and Haden, P. (2006). Parson's programming puzzles: A fun and effective learning tool for first programming courses. In Proceedings of the 8th Australasian Conference on Computing Education - Volume 52, ACE '06, pages 157-163, Darlinghurst, Australia, Australia. Australian Computer Society, Inc.

Piva Jr., D. and Cortelazzo, A. L. (2015). Sala de aula invertida, ambientes de aprendizagem e educação online: a junção de três métodos para potencialização do ensino de algoritmos. In IV Congresso Brasileiro de Informática na Educação - CBIE 2015.

Priesnitz Filho, W., Abegg, I., and Simonetto, E. (2012). Uma abordagem diferenciada no ensino de algoritmos através da utilização de uma lousa digital. GEINTEC - Gestão, Inovação e Tecnologias, 2(2).

Rapkiewicz, C. E., Falkembach, G., Seixas, L., dos Santos Rosa, N., da Cunha, V. V., and Klemann, M. (2006). Estratégias pedagógicas no ensino de algoritmos e programação associadas ao uso de jogos educacionais. RENOTE - Revista Novas Tecnologias na Educação, 4(2).

Salgado, N., Castro, T., and Castro, A. (2013). Aprendizagem colaborativa de programação com scratch e opensimulator. In X Simpósio Brasileiro de Sistemas Colaborativos - SBSC 2013.

Siqueira, L. M. M. and Alcântara, P. R. (2003). Modificando a atuação docente utilizando a colaboração. Revista Diálogo Educacional, 4:1-13.

Valdivia, R., Nussbaum, M., and Ochoa, S. (2009). Modeling a collaborative answer negotiation activity using ims-based learning design. IEEE Transactions on Education, 52:375-384.

Valente, J. A. (2014). A comunicação e a educação baseada no uso das tecnologias digitais de informação e comunicação. Revista UNIFESO - Humanas e Sociais, 1(1):141 166. 